Provided for non-commercial research and education use. Not for reproduction, distribution or commercial use.

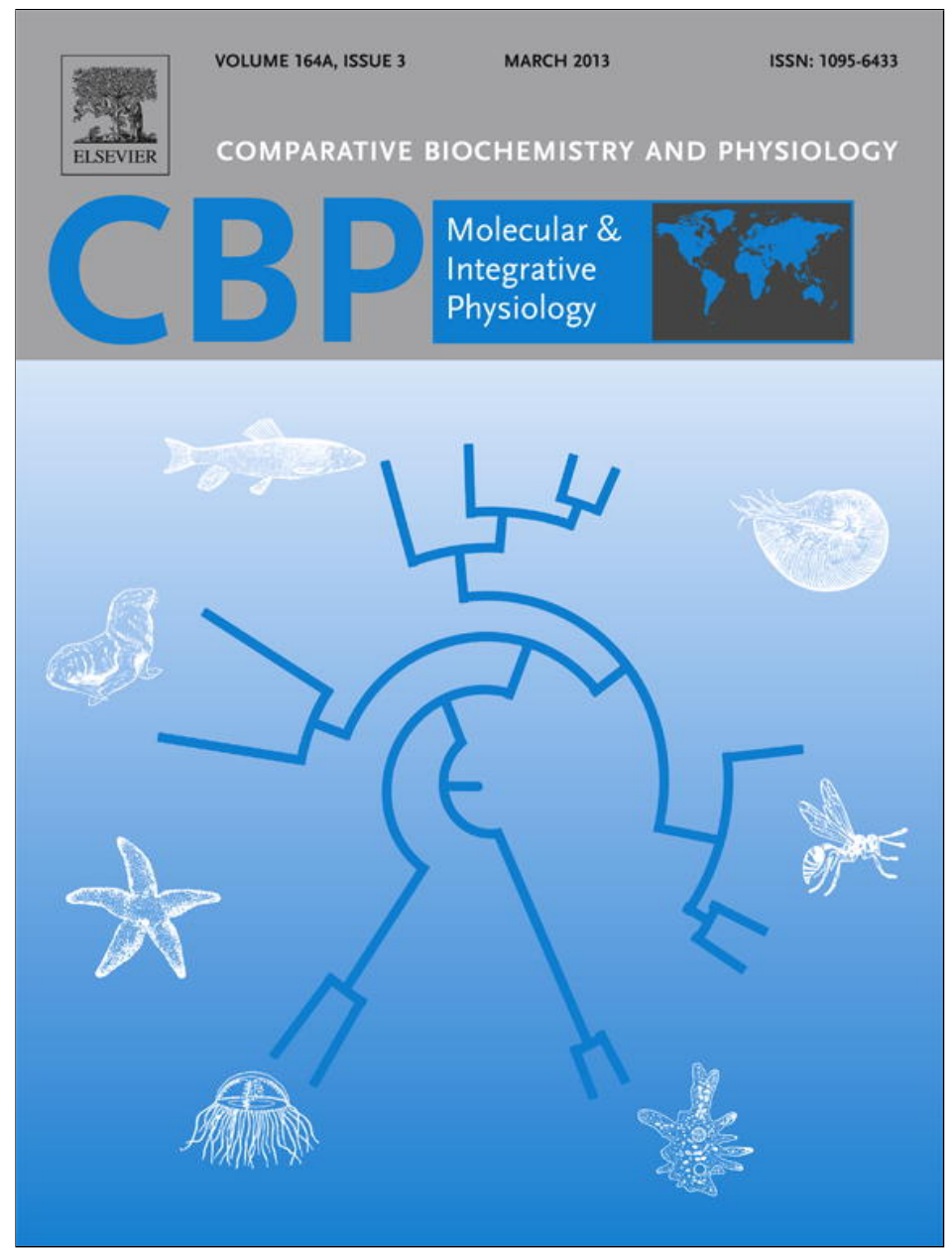

This article appeared in a journal published by Elsevier. The attached copy is furnished to the author for internal non-commercial research and education use, including for instruction at the authors institution and sharing with colleagues.

Other uses, including reproduction and distribution, or selling or licensing copies, or posting to personal, institutional or third party websites are prohibited.

In most cases authors are permitted to post their version of the article (e.g. in Word or Tex form) to their personal website or institutional repository. Authors requiring further information regarding Elsevier's archiving and manuscript policies are encouraged to visit:

http://www.elsevier.com/copyright 


\title{
Characterization of the transport of lysine-containing dipeptides by PepT1 orthologs expressed in Xenopus laevis oocytes
}

\author{
Eleonora Margheritis ${ }^{\text {a,b }}$, Genciana Terova a , Ayodele Stephen Oyadeyi ${ }^{\text {a,b }}$, Maria Daniela Renna a,b, \\ Raffaella Cinquetti ${ }^{a}$, Antonio Peres ${ }^{\text {a }}$, Elena Bossi ${ }^{a}, *$ \\ a Department of Biotechnology and Life Science, University of Insubria, Via J.H. Dunant 3, I-21100 Varese, Italy \\ b School of Biological and Medical Science, University of Insubria, Varese, Italy
}

\section{A R T I C L E I N F O}

\section{Article history:}

Received 28 September 2012

Received in revised form 13 December 2012

Accepted 17 December 2012

Available online 23 December 2012

\section{Keywords:}

Nutrient transport

SLC15A1

$\mathrm{pH}$ dependence

Essential amino acid (EAA)

PepT1

Peptide

\begin{abstract}
A B S T R A C T
During digestion, dietary proteins cleaved in di and tri-peptides are translocated from the intestinal lumen into the enterocytes via PepT1 (SLC15A1) using an inwardly directed proton electrochemical gradient. The kinetic properties in various PepT1 orthologs (Dicentrarchus labrax, Oryctolagus cuniculus, Danio rerio) have been explored to determine the transport efficiency of different combinations of lysine, methionine, and glycine. Species-specific differences were observed. Lys-Met resulted the best substrate at all tested potentials in sea bass and rabbit PepT1, whereas in the zebrafish transporter all tested dipeptides (except Gly-Lys) elicited similar currents independently on the charge position or amino acid composition. For the sea bass and rabbit PepT1, kinetic parameters, $\mathrm{K}_{0.5}$ and $\mathrm{I}_{\max }$ and their ratio, show the importance of the position of the charged lysine in the peptide. The PepT1 transporter of these species has very low affinity for Lys-Lys and Gly-Lys; this reduces the transport efficiency which is instead higher for Lys-Met and Lys-Gly. PepT1 from zebrafish showed relatively high affinity and excellent transport efficiency for Met-Lys and Lys-Met. These data led us to speculate about the structural determinants involved in substrate interaction according to the model proposed for this transporter.
\end{abstract}

(C) 2012 Elsevier Inc. All rights reserved.

\section{Introduction}

The cell membrane is a selective barrier for permeation of nutrient and xenobiotics and the transport across the plasma membrane is a crucial step of the translocation route. The solute enters the animal cell mainly through specialized proteins exploiting the $\mathrm{Na}^{+}$gradient or via uniport or antiport systems; other transporters energize the translocation by a transmembrane electrochemical proton gradient that, due to the negative potential inside the cell, supplies a force sufficient to accumulate nutrients above the extracellular concentration.

PepT1 (SLC15A1) is an electrogenic transporter that uses the inwardly directed proton electrochemical gradient to drive the transport of several di-tripeptides as well as peptido-mimetic molecules into a variety of cells. During digestion, dietary proteins are enzymatically cleaved and degradation products are translocated from the intestinal lumen into the enterocytes via PepT1. Lysine and methionine are two essential amino acids known to be growth-limiting in animals. On the other hand, fish meal (FM) supply has become a limiting factor for the further development of fish feed production, and diets for aquaculture species often have increasing proportions of plant-based ingredients. Although such feeds are effective for raising omnivorous and herbivorous species, the challenge in carnivorous fish is greater. Several studies

\footnotetext{
* Corresponding author. Tel.: + 390332421318 ; fax: + 3903321421300.

E-mail address: elena.bossi@uninsubria.it (E. Bossi).
}

have demonstrated that plant protein-based diets, often deficient in essential amino acids (EAA) such as lysine and/or methionine, caused poor growth performance of carnivorous European sea bass (Dicentrarchus labrax) reared in salt water. For this reason, it has been suggested that EAA supplementation will be suitable in solving the nutritional challenge with formulated purified diets for cultured fish. PepT1 is the major route of intake of small peptides and a better knowledge of its ability to transport lysine- and methionine-containing peptides will help in the formulation of the correct form of EAA to be supplemented in the fish diets.

The overall high degree sequence conservation of PepT1 through evolution (from prokaryotics to mammals) is, not only consistent with its essential role in growth and metabolism, but it also suggests that its biological action may be equally well conserved (Daniel et al., 2006; Solcan et al., 2012). Indeed, data presented in this last recent paper suggest that many functional aspects of the prokaryotic transporter are similar to the mammalian one, demonstrating high conservation of these mechanisms during evolution.

Different animal PepT1 orthologs have been analyzed in order to define a unified model of transport (Renna et al., 2011b), and the effects of temperature (Bossi et al., 2012), by comparing the presteady-state currents in the different species. In the present work, a comparative analysis of transport currents, substrate affinity and transport efficiency was conducted using an electrophysiological approach with the aim of exploring the characteristics of transport of some essential amino acids 
(lysine, methionine) and glycine in different combinations of peptides, in order to evaluate the uptake efficiency of these nutrients by various PepT1 proteins.

\section{Materials and methods}

\subsection{Oocyte expression}

Xenopus laevis oocytes and RNAs were prepared as previously described in detail (Bossi et al., 2007a). To prepare the mRNA, the cDNAs encoding the different orthologs of PepT1 transporters cloned into the pSPORT-1 vector (Invitrogen, Milan, Italy, www.lifetechnologies.com) were linearized with NotI for the rabbit (Oryctolagus cuniculus) PepT1 (rbPepT1) and with HindIII for the seabass (D.labrax) (sbPepT1) and the zebrafish (Danio rerio) (zfPepT1) PepT1. Subsequently cRNAs were synthesized in vitro in the presence of Cap Analog and 200 units of T7 RNA polymerase. All enzymes were supplied by Promega Italia (www.promega.com, Milan, Italy). Oocytes were obtained from adult female X. laevis (Xenopus express, France, www.xenopus.com), the frogs were anesthetized in MS222 (tricaine methanesulfonate salt) (Sigma, Milan, Italy, www.sigmaaldrich.com) $0.10 \% \mathrm{w} / \mathrm{v}$ solution in tap water and portions of the ovary were removed through an incision on the abdomen. The oocytes were treated with collagenase Type IA (Sigma) $1 \mathrm{mg} / \mathrm{mL}$ in calcium-free ND96 for at least $1 \mathrm{~h}$ at $16{ }^{\circ} \mathrm{C}$. After 24 h at $16{ }^{\circ} \mathrm{C}$ in modified Barth's saline solution (MBS), selected oocytes were injected with $12.5 \mathrm{ng}$ of cRNA in $50 \mathrm{~nL}$ of water, using a manual microinjection system (Drummond Scientific Company, Broomall, PA, www.drummondsci.com). The oocytes were then incubated at $16{ }^{\circ} \mathrm{C}$ for 3-4 days in MBS before electrophysiological studies. The experiments were carried out according to the institutional and national ethical guidelines (permit no. 05/12).

\subsection{Point mutations}

Mutations in rabbit and zebrafish PepT1 were obtained by site-directed mutagenesis. Briefly, $20 \mathrm{ng}$ of the plasmids containing the FLAG-wild-type rbPepT1 and the wild-type-zfPepT1 cDNAs was amplified with 2.5 units of $P f u$ DNA polymerase in the presence of overlapping primers containing in their sequences the mutated codons:

\section{rbPepT1_T327I 5'-CAGCCGGATCAGATGCAGATCGTGAACACCATCTTG ATTATTATCC-3' zfPepT1_I334T 5'-GCCAGATCAGATGCAGACCGTGAACCCTATACTG-3'.}

PCR amplification was performed with 25 thermal cycles at $95{ }^{\circ} \mathrm{C}$ for $30 \mathrm{~s}, 55^{\circ} \mathrm{C}$ for $1 \mathrm{~min}$, and $68{ }^{\circ} \mathrm{C}$ for $14 \mathrm{~min}$. Then, 10 units of $D p n I$ were added directly to the amplification reaction, and the samples were incubated for $1 \mathrm{~h}$ at $37^{\circ} \mathrm{C}$ to digest the parental, methylated DNA. JM109 competent cells were finally transformed with $10 \mu \mathrm{L}$ of the reaction mixture and plated onto LB-ampicillin plates (Liu and Naismith, 2008; Edelheit et al., 2009; Bossi et al., 2011). Plasmids were purified and sequenced (Eurofin MWG Operon, Ebersberg, Germany, www. eurofinsdna.com/) to confirm the nucleotide substitutions.

\subsection{Single-oocyte chemiluminescence}

To evaluate the expression at the oocyte plasma membrane, we used single-oocyte chemiluminescence (SOC) to quantify a tagged protein expressed at the cell surface (Bossi et al., 2011). Briefly, oocytes expressing FLAG-wild-type rbPepT1 and FLAG-rbPepT1 T327I, as well as non-injected oocytes, were fixed with $4 \%$ paraformaldehyde in ND96, then rinsed for three times in cold ND96 for $5 \mathrm{~min}$ and, after $1 \mathrm{~h}$ of incubation in blocking solution (BSA 1\% + ND96 pH 7.6) they were incubated for $1 \mathrm{~h}$ in primary mouse anti-FLAG M2 (Sigma, Milan, Italy, www.sigmaaldrich.com) monoclonal antibody
( $1 \mu \mathrm{g} / \mathrm{mL}$ in $1 \%$ BSA-ND96) (all steps at $4{ }^{\circ} \mathrm{C}$ ). At this point the oocytes were transferred at room temperature and kept for $1 \mathrm{~h}$ in peroxidase-conjugated goat anti-mouse IgG (HRP-IgG) $1 \mu \mathrm{g} / \mathrm{mL}$ (www.jacksonimmuno.com). For chemiluminescence readings, each oocyte was transferred into a well of a 96-well plate (Assay Plate White not treated flat bottom, Corning Costar, www.corning.com) filled with $50 \mu \mathrm{L}$ SuperSignal Femto (Pierce, Euroclone, Milan, Italy, www. euroclonegroup.it). Chemiluminescence was quantified with a Tecan Infinity 200 microplate reader. The plates were read not later than 5 min after the transfer of the first oocyte. The data were then acquired at least three times in $10 \mathrm{~min}$. Results were normalized to the mean value of wild-type FLAG-PepT1 for each batch and are given in arbitrary units (AU).

\subsection{Electrophysiology and data analysis}

Measurements of the currents generated by the transporters in controlled voltage conditions were performed using the two-electrode voltage clamp (TEVC) technique (GeneClamp, Molecular Devices, Sunnyvale, CA, USA) (Giovannardi et al., 2007). Intracellular glass microelectrodes, filled with $\mathrm{KCl} 3 \mathrm{M}$ and with tip resistance between 0.5 and $4 \mathrm{M} \Omega$ were used. Agar bridges ( $3 \%$ agar in $3 \mathrm{M} \mathrm{KCl}$ ) connected the bath electrodes to the experimental chamber. The holding potential $\left(\mathrm{V}_{\mathrm{h}}\right)$ was $-60 \mathrm{mV}$. Voltage pulses from $-140 \mathrm{mV}$ to $+40 \mathrm{mV}$ in $20 \mathrm{mV}$ increments were applied for $200 \mathrm{~ms}$. Data were analyzed using Clampfit 10.2 (Molecular Devices, www.moleculardevices.com), while statistics and figures were done with Origin 8.0 (originalLab Corp., Northampton, MA, USA, www.originlab.com).

\subsection{Solutions}

The oocyte culture and washing solutions had the following composition (in mM), calcium-free ND96: 96, $\mathrm{KCl} 2, \mathrm{MgCl}_{2}$ 1, Hepes 5, pH 7.6; ND96: $\mathrm{NaCl}$ 96, $\mathrm{KCl} 2, \mathrm{MgCl}_{2}$ 1, $\mathrm{CaCl}_{2}$ 1.8, Hepes 5, pH 7.6; MBS: $\mathrm{NaCl} 88$, $\mathrm{KCl} 1, \mathrm{NaHCO}_{3} 2.4$, Hepes $15, \mathrm{Ca}\left(\mathrm{NO}_{3}\right)_{2} 0.30, \mathrm{CaCl}_{2} 0.41, \mathrm{MgSO}_{4} 0.82$, sodium penicillin $10 \mu \mathrm{g} / \mathrm{mL}$, streptomycin sulfate $10 \mu \mathrm{g} / \mathrm{mL}$, gentamicin sulfate $100 \mu \mathrm{g} / \mathrm{mL}, \mathrm{pH} 7.6$; PBS: $\mathrm{NaCl} 138, \mathrm{KCl} 2.7, \mathrm{Na}_{2} \mathrm{HPO}_{4} 10$, $\mathrm{KH}_{2} \mathrm{PO}_{4} 2$, pH 7.6. The external control solution during the electrophysiological recordings had the following composition $(\mathrm{mM})$ : $\mathrm{NaCl}, 98$; $\mathrm{MgCl}_{2}, 1 ; \mathrm{CaCl}_{2}, 1.8$, Hepes $5 \mathrm{mM}$. The final pH values (6.5-7.5) were adjusted with $\mathrm{NaOH}$. The dipeptide substrates were added at the indicated concentrations. Experiments were conducted at room temperature $\left(20-25^{\circ} \mathrm{C}\right)$.

The peptides tested were: Glycine-Glutamine, Lysine-Lysine, Methionine-Lysine, Lysine-Glycine (Sigma, Milan, Italy) Glycine-Lysine, Lysine-Methionine, Lysine-Lysine-Lysine (Genicbio, Shanghai, China, www.genicbio.com) at concentrations from $0.1 \mathrm{mM}$ to $30 \mathrm{mM}$.

\subsection{Sequence alignment}

PepT1 sequences were obtained from NCBI database (GenBank accession no. AAQ65244.1 for Danio rerio, AAK39954.1 for Gallus gallus, NP_999512.1 for Sus scrofa, AAK14788 for Ovis aries, NP_001075806 for Oryctolagus cuniculus, NP_005064 for Homo sapiens, ACI49693.2 for Dicentrarchus labrax, 2XUT_B for Shewanella oneidensis, 4APS_B for Streptococcus thermophilus, and PepT1, respectively), aligned with ClustalW (www.ebi.ac.uk/clustalw2) and the consensus sequences were visualized with Jalview program (www.jalview.org).

\section{Results}

\subsection{Transport current}

Measurements of the transport associated currents generated by the transporters, in the presence of different substrates, were performed at constant $(\mathrm{Vh}=-60 \mathrm{mV}$ ) (Fig. $1 \mathrm{~A}, \mathrm{~B}, \mathrm{C})$, or at different membrane 
A rbPepT1
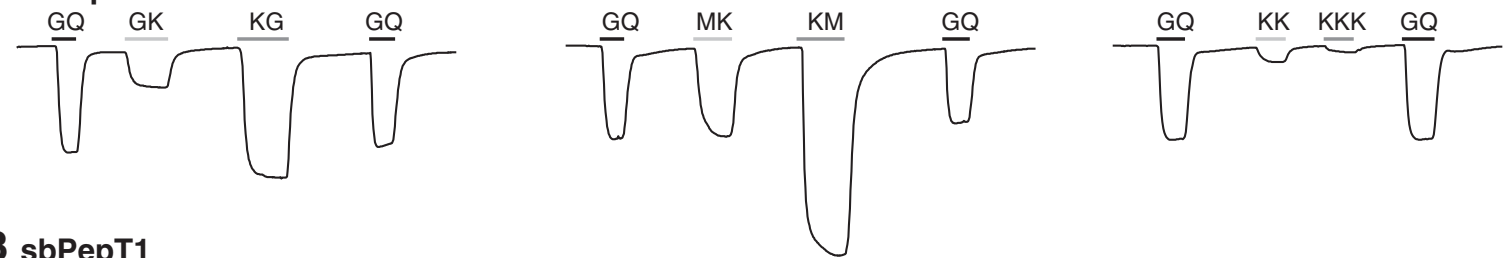

B sbPepT1
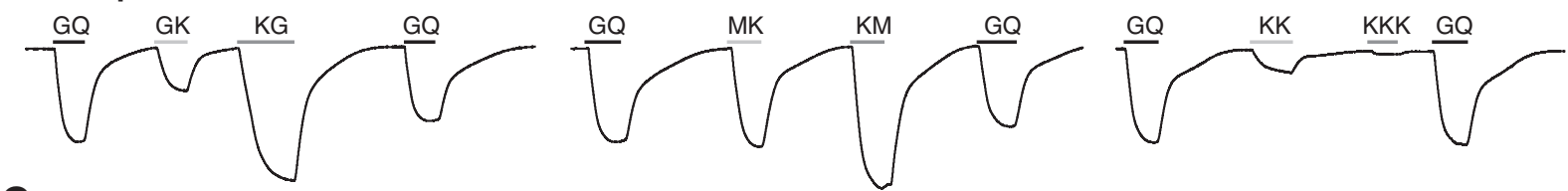

C zfPepT1
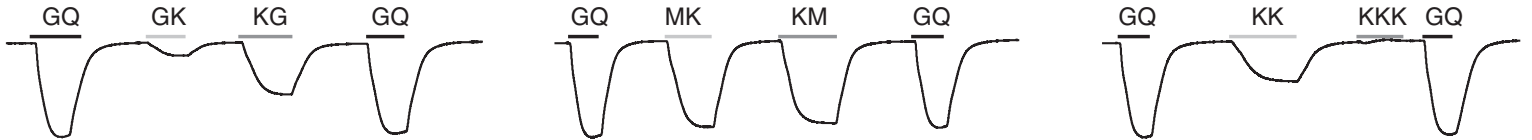

Substrates $1 \mathrm{mM}, \mathrm{pH} 7.5$ $\mathrm{Vh}=-60 \mathrm{mV}$

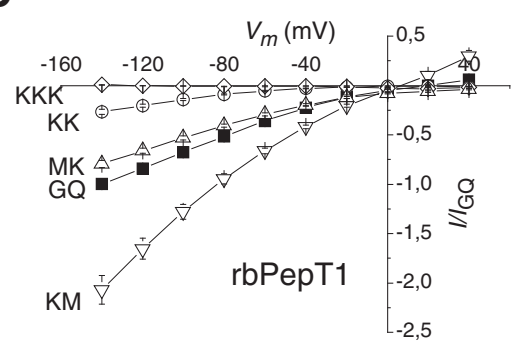

E

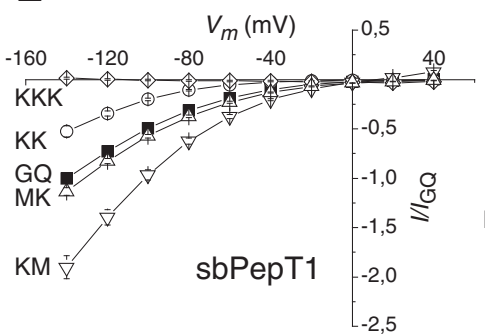

F

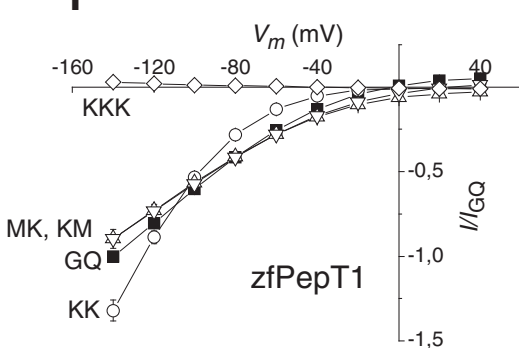

Fig. 1. Transport Currents. A,B, C: Representative traces of transport-induced current in three orthologs (rabbit, sea bass and zebrafish) heterologously expressed in Xenopus laevis oocytes, at the holding potential of $-60 \mathrm{mV}$. Different combinations of lysine, glycine and methionine are indicated, the first and the last substrate is glycine-glutamine as reference, traces are normalized to the first glycine-glutamine response. D, E, F: Current-voltage relationships of transport-induced current in the three PepT1 species, by using a voltage pulse protocol from $\mathrm{V}_{\mathrm{h}}=-60 \mathrm{mV}$. Data are obtained by subtracting the traces recorded in the absence from those recorded in the presence of the indicated substrate ( 1 mM), and were normalized to the value at $-140 \mathrm{mV}$ for glycine-glutamine. Values are means $\pm \mathrm{SE}$ from 18 to 20 oocytes from different batches in each group.

voltages (Fig. 1D,E,F) and in two pH conditions (Fig. 2) on X. laevis oocytes expressing sbPepT1 (D.labrax), rbPepT1 (O. cuniculus) and zfPepT1 (D. rerio).

The recordings at $-60 \mathrm{mV}$ allow to rapidly compare similarities and differences among species.

For all the tested orthologs the Lys-Lys-Lys peptide elicits only a negligible current. With Lys-Lys dipeptide small currents are visible in rabbit and sea bass PepT1 (about 15-20 nA) (Fig. 1A and B), while a larger current (up to $100 \mathrm{nA}$ ) can be recorded in zebrafish (Fig. 1C). Association of lysine with a neutral amino acid shows that the position of the charged residue establishes the amplitude of the transport current. In fact when the currents evoked by Gly-Lys (GK) and Lys-Gly (KG) are compared, it is clearly visible that with the charged amino acid in the first position the current generated by the transport of the dipeptide is increased. Moreover, in rabbit and sea bass, the transport-associated current becomes larger than the reference current generated by Gly-Gln (GQ). When the neutral amino acid is methionine the differences in current amplitude between the two dipeptides are preserved and the importance of the charge position is confirmed with the exception of the zebrafish PepT1 in which the dipeptides Lys-Met (KM) and Met-Lys (MK) show comparable efficiency.

Furthermore, in zfPepT1, the current generated by glycine and lysine (GK and KG), and methionine and lysine (MK and $\mathrm{KM}$ ) is always smaller than that generated by GQ (Fig. 1C and F).

To check whether the membrane voltage can affect the transport of charged dipeptides, the three PepT1 proteins were tested in the presence of lysine-peptides (KK and KKK), and lysine/methionine dipeptides (KM and MK), using Gly-Gln as reference. The I/V relationships at pH 7.5 are reported in Fig. 1D for rabbit, Fig. 1E for sea bass and Fig. 1F for zebrafish.

Species-specific differences are observed in the potency order among the various substrates (all at $1 \mathrm{mM}$ ), and in the voltage-dependence of the current amplitude. In particular, Lys-Met was the best substrate at all tested potentials in sea bass PepT1 (Fig. 1E), as well as in the rabbit transporter (Fig. 1D), while in the zebrafish ortholog (Fig. 1F) not only all tested dipeptides elicited similar currents, independently on the charge position or amino acid composition, but at the most negative potential the dipeptide Lys-Lys enhanced the transport current, amplifying the differences among orthologs. On the contrary, in rabbit and sea bass PepT1 the dipeptide Lys-Lys was only modestly transported (Fig. 1D and E). Finally the tripeptide Lys-Lys-Lys did not give rise to any current at pH 7.5 independently on voltage in all the tested PepT1 proteins.

\section{2. $\mathrm{pH}$ dependence of transport current}

Different from other vertebrate orthologs, which work, under substrate saturation conditions, basically in a pH-independent manner, zfPepT1, shows increased maximal transport rates at alkaline extracellular pH (Verri et al., 2003). These findings may be correlated to a very short intestinal tract, typical of carnivorous fish, or to its stomachless condition (i.e. no acidic content is released into the proximal intestine). The characteristics of the sea bass PepT1 transporter were reported in 
sea bass

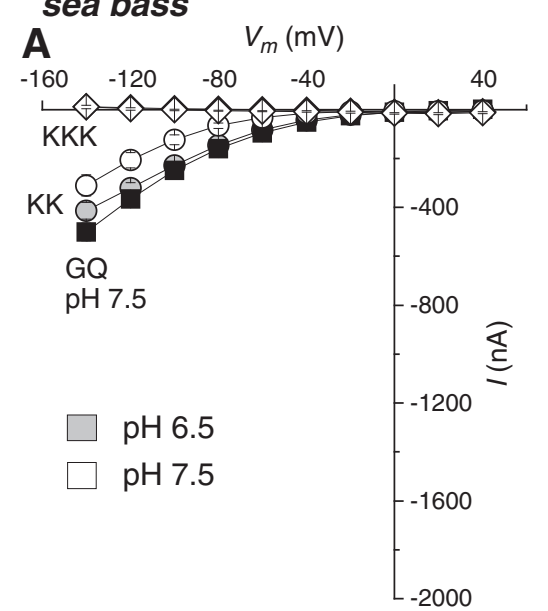

zebrafish

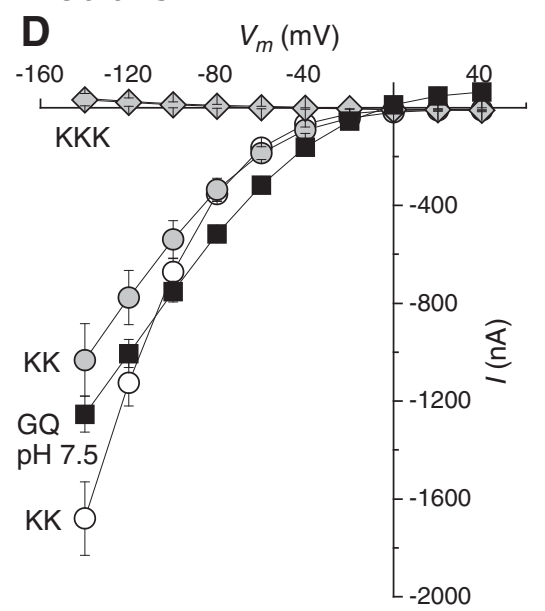

B

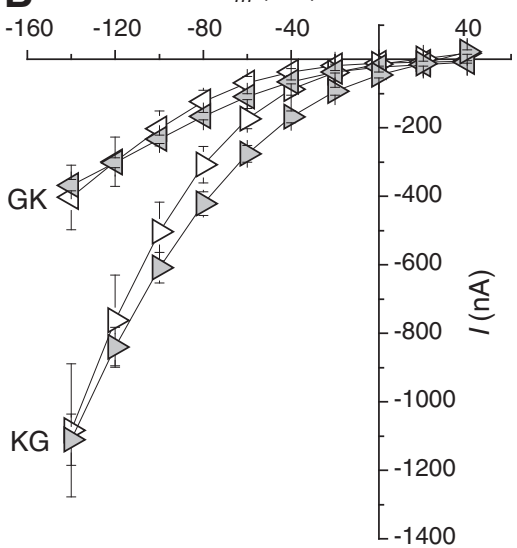

E

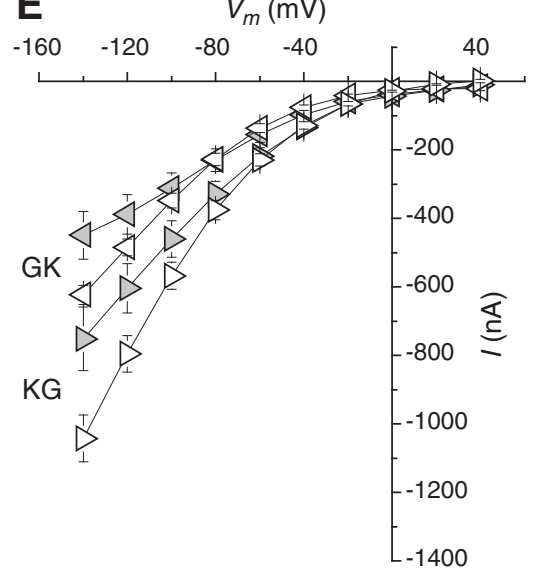

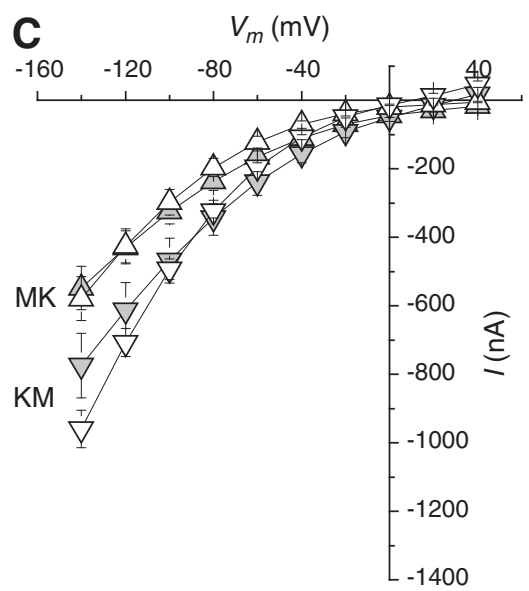

F $\quad V_{m}(\mathrm{mV})$

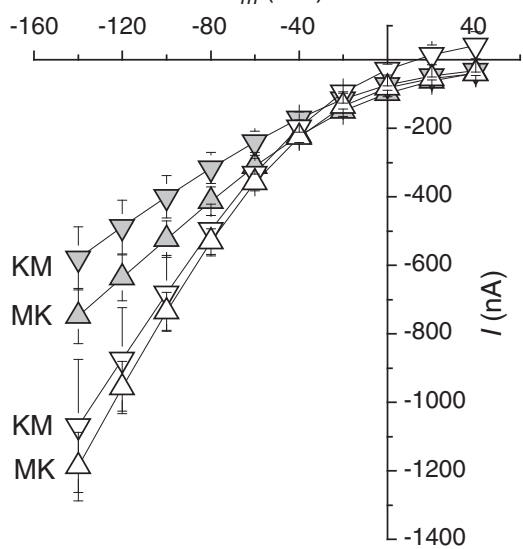

Fig. 2. pH Effects on Transport Current. Current-voltage relationships of transport-induced current in sea bass (A, B and C), and zebrafish (D, E and F) recorded from -140 to $+40 \mathrm{mV}$ at pH 6.5 (light gray symbols) and pH 7.5 (empty symbols), GQ values at pH 7.5 were reported as reference (black square). Values are means \pm SE from 8 to 20 oocytes from 3 to 5 batches in each group.

Sangaletti et al. (2009). The different properties of the two orthologs encouraged us to test if at pH 6.5, sea bass and rabbit could be able to efficiently transport the multiple-charged peptides. The results at $\mathrm{pH} 7.5$ and 6.5 for sea bass and zebrafish are illustrated in Fig. 2 (the data for rabbit, very similar to sea bass, are not shown).

At pH 6.5 no currents were generated by Lys-Lys-Lys $1 \mathrm{mM}$, at pH 7.5 Lys-Lys gave rise to a small current in sea bass (Fig. 2A) and rabbit (not shown), and when the $\mathrm{pH}$ was lowered to 6.5 a small but significant increase was observed at voltage values more negative than $-60 \mathrm{mV}$.

In zfPepT1 the currents generated by Lys-Lys at the two pH values were significantly different from each other only at -120 and $-140 \mathrm{mV}$, confirming previous results (Verri et al., 2003).

The importance of the position of the charged amino acid in the dipeptide was examined, testing KM, MK and KG and KG dipeptides $(1 \mathrm{mM})$ at $\mathrm{pH} 6.5$ and 7.5 .

In sbPepT1 no effect of $\mathrm{pH}$ was observable in $\mathrm{MK}$ and $\mathrm{KM}$ induced-currents (Fig. 2C) except for KM at the most negative voltages. When the same dipeptides were tested in zfPepT1, the amplitude of the current for both KM and MK was increased by external alkalinization (Fig. 2F).

The use of peptides containing glycine has highlighted the differences among the species described above, that is to say that the currents elicited by GK and KG, seem to be independent on the alkalinity or acidity of the external solution in sbPepT1 (and in rabbit), while they are pH-dependent in zebrafish (Fig. 2B and F).

\subsection{Transport efficiency}

To complete these outcomes the apparent affinity for these substrates was estimated for the sea bass and zebrafish PepT1 proteins.

The amount of substrate able to generate half of the maximal current $\left(\mathrm{K}_{0.5}\right)$ at each voltage value between $-140 \mathrm{mV}$ and $0 \mathrm{mV}$ was calculated from dose-response experiments (from $0.1 \mathrm{mM}$ to $30 \mathrm{mM}$ ), and the results are reported in Fig. 3A for sea bass and Fig. 3B for zebrafish.

The first remark is that, as expected, the Lys-Lys dipeptide has a very low apparent affinity in both orthologs. The affinity for GK was estimated only for sbPepT1, because for zebrafish PepT1 the GK concentrations needed to approach saturation were extremely high and not experimentally achievable.

The values calculated at the different voltages for other substrates (KG, KM, MK and GQ as reference) are detailed in Fig. 3. They are very similar in sea bass (Fig. 3A) and rabbit (not shown), and considering only KM and MK, in zfPepT1 as well (Fig. 3B). Therefore these results confirm previous data (Kottra and Daniel, 2001; Kottra et al., 2002; Ronnestad et al., 2010; Verri et al., 2010; Bossi et al., 2011; Renna et al., 2011a,b; Bossi et al., 2012) and particularly the lower affinity of zfPepT1 for KG ( $3.25 \pm 0.52$ at $-40 \mathrm{mV}$, pH 7.5), compared to sbPepT1 $(0.75 \pm 0.06$ at $-40 \mathrm{mV}, \mathrm{pH} 7.5)$.

Finally the efficiency of the transport of lysine-containing dipeptides was investigated. From the dose-response curves the $I_{\max }$ (maximal current) was determined at different voltages from -140 to $-20 \mathrm{mV}$ and the ratio $\mathrm{I}_{\max } / \mathrm{K}_{0.5}$ was calculated. This ratio 
A
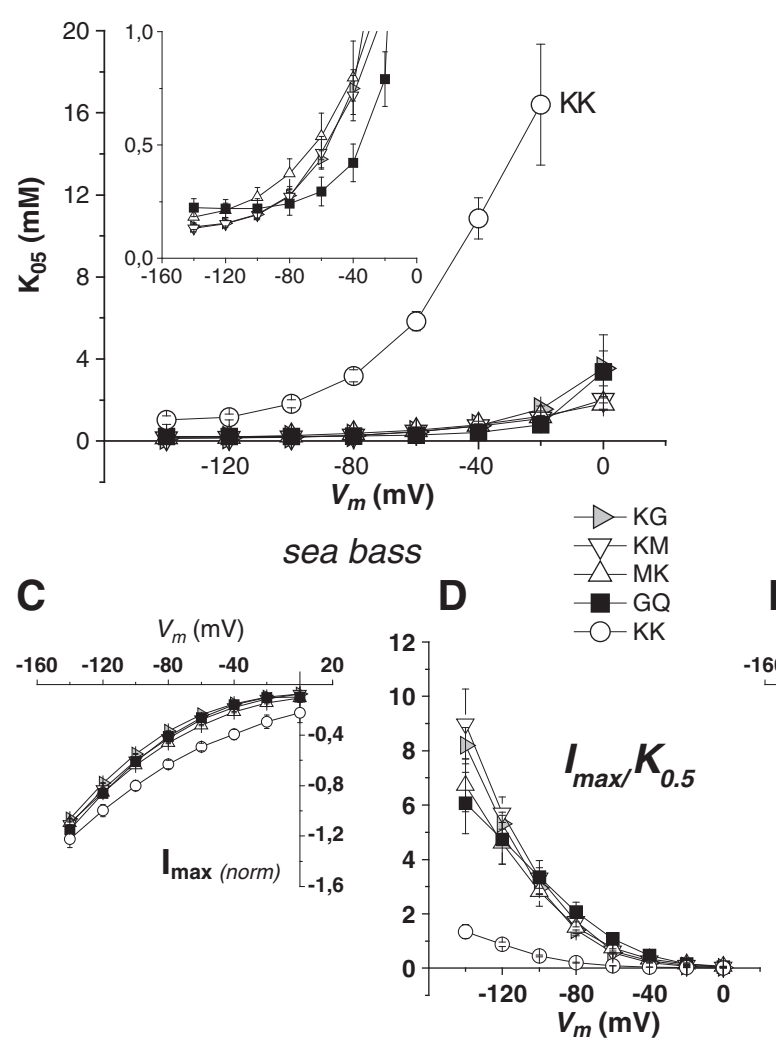

B

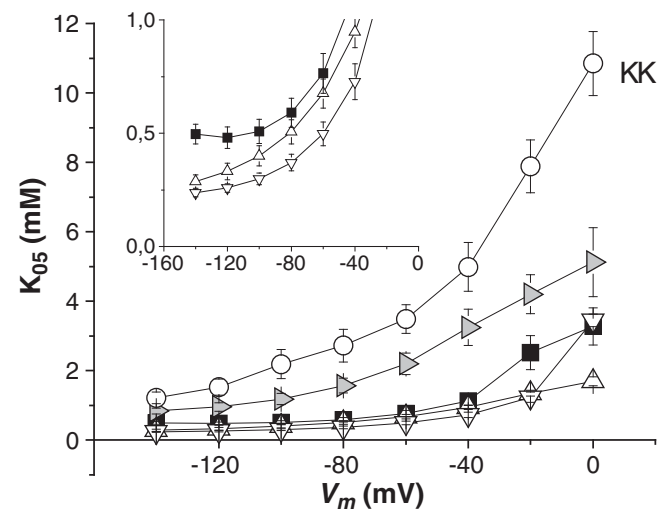

zebrafish
E $\quad \mathbf{F}$

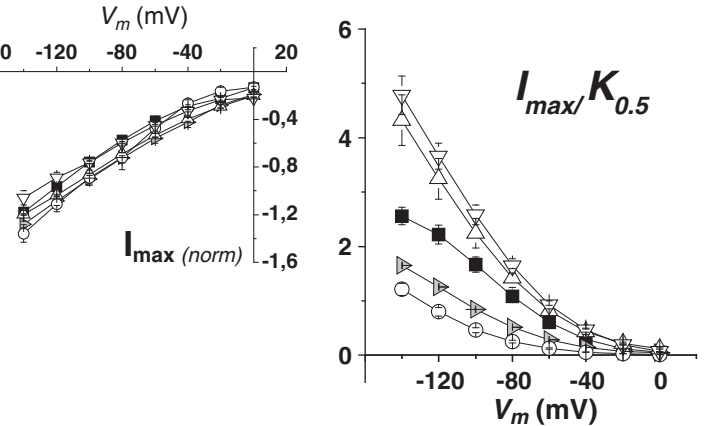

Fig. 3. Kinetic parameters for sea bass (A, C, D) and zebrafish (B, E, F). The dose-response current values were fitted with a logistic curve to obtain the substrate concentration eliciting half $I_{\max }\left(K_{0.5}\right)$ at each voltage: A and B, the insets are enlargements of $K_{0.5}$ between 0 and 1 mM. The relative maximal current $\left(I_{\text {max }}\right)$ at each voltage is plotted in $C$ and in $\mathrm{E}$, the ratio of relative $\mathrm{I}_{\max } / \mathrm{K}_{0.5}$, an index of the transport efficiency, is plotted in $\mathrm{D}$ and $\mathrm{F}$. Data were normalized to the value of each substrate at the concentration of $3 \mathrm{mM}$ at $-140 \mathrm{mV}$. Values are mean $\pm \mathrm{SE}$ from 8 to 20 oocytes from different batches in each group.

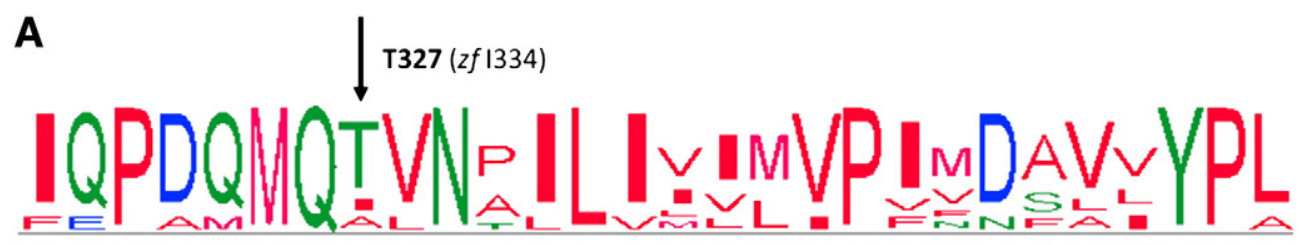

I QPDQMQT VNP I L I V I MVP I MDAVVYPL

B

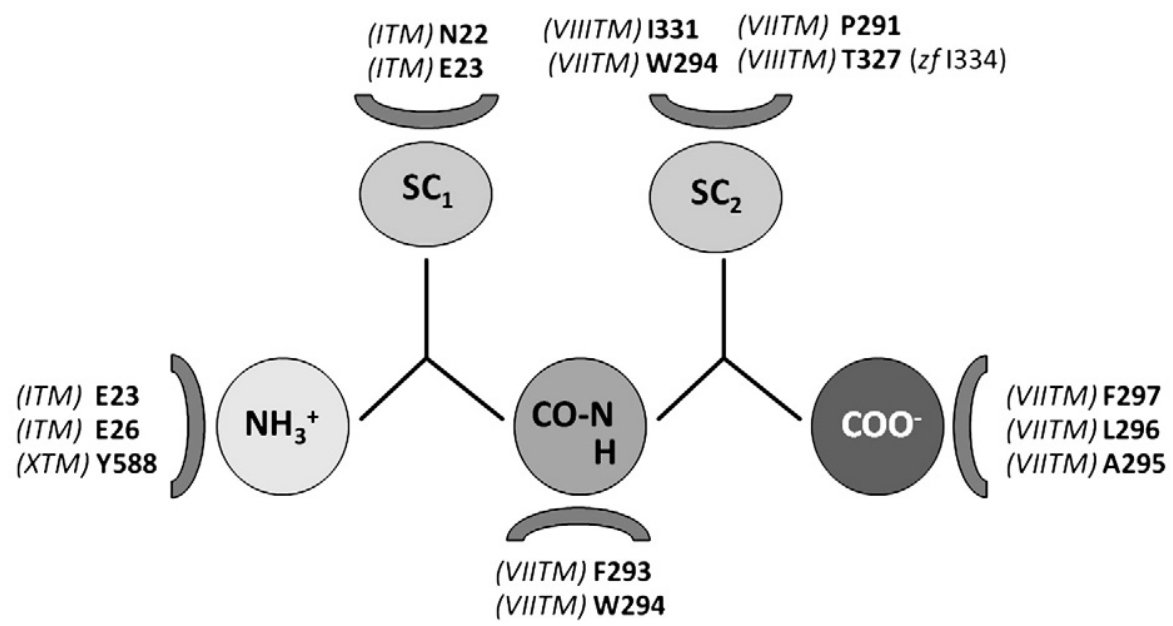

Fig. 4. Alignment of the PepT1 orthologs. A. The consensus sequence of VIII transmembrane domain is presented as sequence logo. The frequency of occurrence at that particular amino acid is symbolized by the height of a given letter. B. Model of PepT1 interaction modified by Pedretti et al. (2008). 
corresponds to the slope of the Michaelis-Menten relationship at zero substrate concentration, and represents an index of the transport efficiency.

In sea bass (and rabbit PepT1) this parameter demonstrates the importance of the position of lysine in the dipeptide. This protein has low affinity for Lys-Lys $(10.86 \pm 1.01$ at $-40 \mathrm{mV}, \mathrm{pH} 7.5)$ and Gly-Lys $(9.73 \pm 1.99$ at $-40 \mathrm{mV}, \mathrm{pH} 7.5)$ and this strongly reduces the transport efficiency; for other tested dipeptides, the slight difference in affinity and $I_{\max }$, results in a higher transport efficiency for Lys-Met and Lys-Gly. In zfPepT1 relatively high affinity and excellent transport efficiency are shown for Met-Lys and Lys-Met, while decreased efficiency is found for Lys-Gly.

\subsection{Molecular determinant of substrate interaction}

The differences in substrate transport kinetics reported above invited us to look for the structural determinants involved. Considering the structural data derived from the crystallographic approaches (Newstead, 2011) and their connection with functions reported in a recent paper (Solcan et al., 2012), as well as the indications derived from molecular modeling (Meredith and Price, 2006; Pedretti et al., 2008; Meredith, 2009), we looked for residues that may account for the particular behavior of zebrafish. According to the reports cited above, the only residue involved in substrate interaction that differs between zebrafish and rabbit or sea bass (and many others) is residue 327 (rabbit numbering) in the VIII transmembrane domain (TM) (Fig. 4B). Therefore, we replaced threonine 327 with isoleucine in the rabbit protein (rbPepT1 T327I). rbPepT1 was selected because its kinetic properties are similar to sea bass and it includes a modification in the extracellular loop 5 that is a "flag" tag (Mertl et al., 2008) that permits immunochemical recognition. This aspect is particularly important in the mutants, because it allows to quantify the amount of the protein inserted in the membrane and if the mutation produces a non- (or less) functional protein (Bossi et al., 2011). In this case rbPepT1 T327I was correctly
A rbPepT1 WT
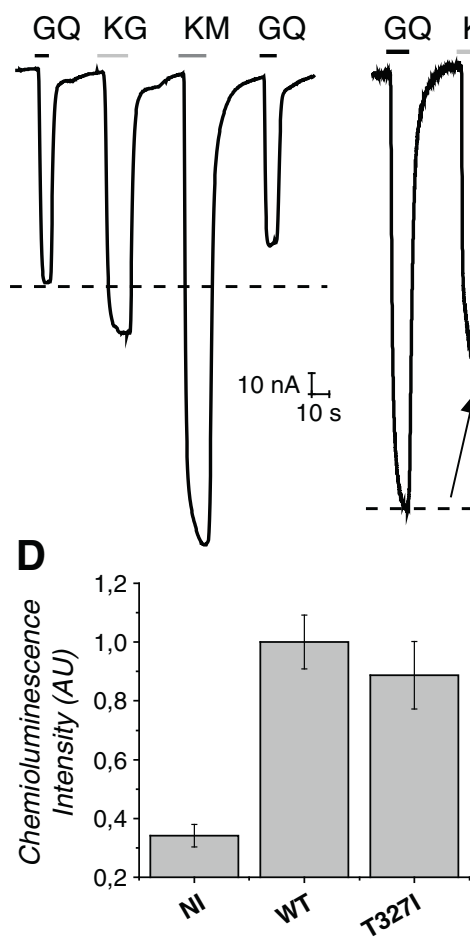

E

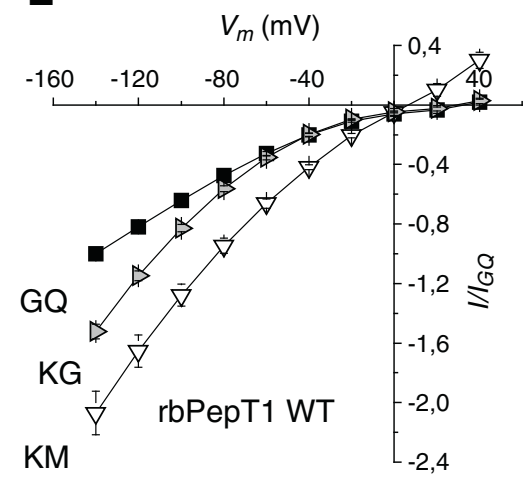

rbPepT1 T327।
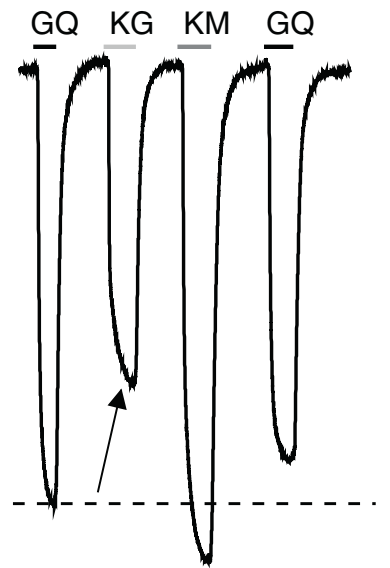

C zfPepT1 WT

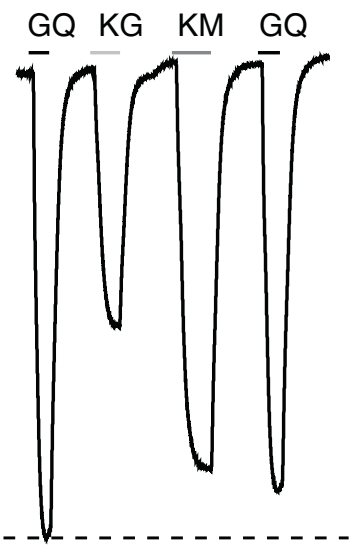

Substrates $1 \mathrm{mM}$

$\mathrm{pH} 7.5$

$\mathrm{Vh}=-60 \mathrm{mV}$
F

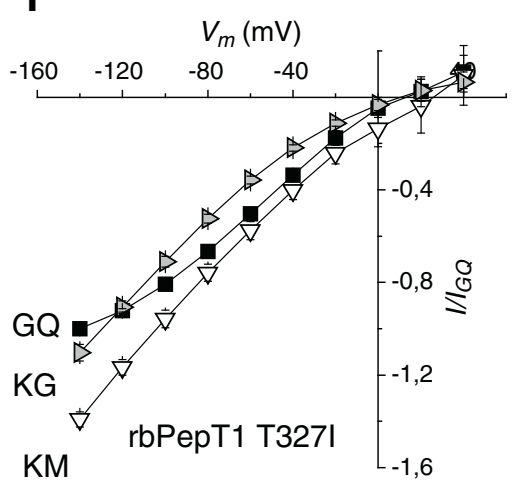

Fig. 5. Behavior of the rbPepT1T327I mutant. Top row: transport currents elicited by the indicated substrates at $-60 \mathrm{mV}$ and pH $7.5 \mathrm{in}$ the wild type rbPepT1 (A), in rbPepT1 T327I (B) and in wild type zfPepT1 (C). The dashed line indicates the level of the Gly-Gln current to point out that only in rbPepT1 wt Lys-Gly is able to generate a current larger than Gly-Gln. D: Single oocyte chemiluminescence normalized to the value of the wild-type protein. Data are expressed as arbitrary units (AU) from 20 oocytes of at least 3 batches. E and F: I/V relationships of the transport associated currents for rbPepT1 wild-type and T327I, normalized to the current of Gly-Gln at pH 7.5 at - 140 mV. The substrates are Gly-Gln, Lys-Gly and Lys-Met all at $1 \mathrm{mM}$. 
expressed on the membrane as shown by the SOC (single oocyte chemiluminescence) data Fig. 5D. From the functional point of view the substitution of threonine, one of "the most frequent residues", (Fig. 4A) (Pedretti et al., 2008) involved in ligand recognition with isoleucine present in zebrafish, alters the behavior of the protein (Fig. 5A,B and C).

Principally the mutation affects the interaction with dipeptides: the potency order of their transport currents was modified. As can be seen from the recording at $-60 \mathrm{mV}$ (arrow) (Fig. 5A and B) and from the I/V relationships (Fig. 5E and F). These alterations were highlighted by investigating the kinetic parameters of the transport in the T327I mutant in the presence of Lys-Gly and Lys-Met dipeptides (Fig. 6). Not only the apparent affinity for Gly-Gln was comparable to that of the zebrafish protein (Fig. $3 \mathrm{~B}$ and $\mathrm{F}$ ) with similar shape of the affinity/voltage curve, but rPepT1 T327I showed also an impaired transport efficiency (Fig. 6C and D); with values closer to those of zebrafish. In the rabbit PepT1 T327I the Lys-Gly affinity and the transport efficiency (Fig. 6C and D) differed from the parameters calculated for the wild type (Fig. 6A and B) and sea bass transporters (Fig. 3A and D) (Verri et al., 2003; Sangaletti et al., 2009; Bossi et al., 2012). The substitution of the threonine with isoleucine in the VIII TM changed also the Lys-Met affinity and transport efficiency. Overall the transport characteristics in the mutant are significantly altered with respect to substrate interaction, i.e. they change the affinity and consequently the transport efficiency but they have no effect on the $\mathrm{pH}$ dependence of the tested peptides (data not shown). The opposite mutation in zebrafish (zfPepT1 I334T) showed only very small currents upon addition of the various substrates, too small to perform a complete electrophysiological and kinetic characterization (not shown).

\section{Conclusions}

This research started with the goal to determine the ability of PepT1 to transfer lysine-containing peptides into the enterocytes, in order to suggest optimized forms of EAA supplementation, in particular for aquaculture. The focus on PepT1 has derived from the knowledge that this transporter can potentially transport all 400 di- and 8000 tripeptides that result from merging the 20 diverse amino acids (Daniel and Kottra, 2004). The transport energetic efficiency derives from the fact that 2 or 3 amino acids can be transported into the enterocyte by PepT1 with the same energetic cost necessary to transport a single free amino acid. In addition, it is recognized that species or individuals with reduced amino acid transport are still capable to assimilate EAA validating the ability of PepT1 to move the necessary dietary AA to balance the insufficiency of free amino acid transport (Gilbert et al., 2008). Moreover an increasing number of researchers in biological

\section{rbPepT1}
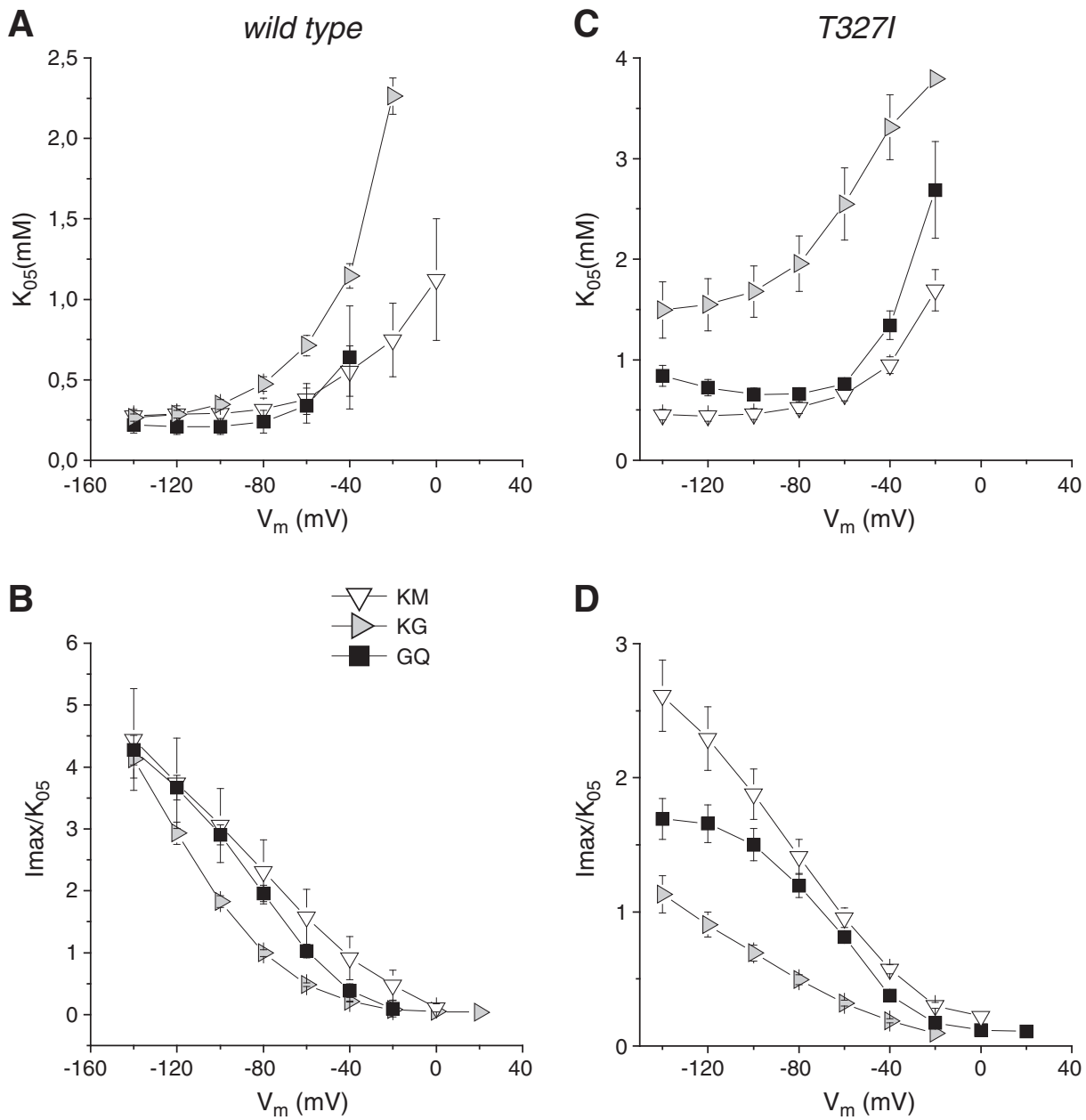

Fig. 6. Kinetic parameters for rbPepT1 wild type (A, B) and rbPepT1 T327I (C, D). The dose-response current values were fitted as indicated in Fig. 3. A and B for the wild type, the $\mathrm{K}_{0.5}$ and the ratio of relative $\mathrm{I}_{\mathrm{max}} / \mathrm{K}_{0.5}$, an index of the transport efficiency, in $C$ and $\mathrm{D}$, the same data for the T327I mutants. Data were normalized to the value of each substrate at the concentration of $3 \mathrm{mM}$ at $-140 \mathrm{mV}$. Values are mean $\pm \mathrm{SE}$ from 4 to 15 oocytes from at least 2 different batches in each group. 
sciences are currently focusing on and discussing the potential role of peptide transport for the uptake of dietary AA in animals. In particular fish represent an excellent model for studying the effects of protein administration on animal growth because of the direct correlation that exists between dietary protein availability and accretion of body mass in these vertebrates. The observation that teleosts can efficiently use dietary di/tri-peptides for development, growth, and metabolism and, consequently, that balanced peptide-based diets or peptide rather than free AA supplementation would be highly beneficial in solving the nutritional inadequacy problems of formulated feeds for cultivated fish (Verri et al., 2011) underlines the necessity to better understand the translocation mechanism of di and tri-peptide. Data about Lys-dipeptide transport kinetics of PepT1 in fish are scarce (Ronnestad et al., 2010; Verri et al., 2010) and the data from mammalian species report affinity values measured in the absence of voltage control or at a single membrane voltage (Pan et al., 2001; Chen et al., 2002a,b; Klang et al., 2005; Ronnestad et al., 2007). In this paper we have considered PepT1 derived from three different species: from sea bass that is important in Mediterranean aquaculture, from rabbit, in which PepT1 is well characterized and from zebrafish that is a well known model organism.

The first result revealed that sea bass PepT1 behaves more like the rabbit one, than like the phylogenetically closer fish model, zebrafish. For sea bass and rabbit PepT1 the transport efficiency of lysine-containing peptides depends on the position of the charged amino acid as established for the human form (Vig et al., 2006). The charge position determines the affinity and consequently, at a given substrate concentration, the amount of dipeptide transferred into the cell. The PepT1 transporter of the other teleost, the model organism zebrafish, shows instead some differences: in this case the transport is regulated by the $\mathrm{pH}$ of the external solution.

The nutritional importance of these findings is a better knowledge of the transport kinetic characteristics, which can suggest the best EAA combination to be used for diet supplementation. Besides these findings warn about the necessity of identifying the appropriate model for a correct investigation (Verri et al., 2010). Suggestion in this direction can come from functional and structural studies (Sangaletti et al., 2009; Newstead et al., 2011; Solcan et al., 2012), amino acid sequence comparison (Ronnestad et al., 2007; Wang et al., 2010) and molecular modeling (Meredith and Price, 2006; Pedretti et al., 2008; Meredith, 2009).

In the oocyte expression approach, proteins from different species are expressed in a unified environment in terms of membrane composition, solute concentrations at both sides of the membrane, $\mathrm{pH}$, temperature and, in electrophysiological studies, in controlled voltage condition. This approach allows to compare proteins in the same laboratory conditions with advantages and disadvantages (Binda et al., 2002; Bossi et al., 2007b, 2012; Peres et al., 2012), but under standardized protocols in conditions otherwise impossible to test.

The highly conserved sequence and the differences in functionality are a good tool for investigating the kinetic characteristics of different transporter orthologs (Soragna et al., 2004; Castagna et al., 2009; Bossi et al., 2012). In the present paper, focusing the attention on the region involved in substrate interaction and protein functionality, we have identified a residue significant for determining the characteristics of transport in zfPepT1. The data obtained for rabbit PepT1 T327I suggest that threonine, very highly conserved in mammalian and fish orthologs (Fig. 4) is involved in substrate selectivity and affinity, but also hint that other, not yet discovered, amino acid residues are likely to be involved in proton interaction, as the $\mathrm{pH}$ dependence was not altered in the mutant.

In conclusion the findings of this research have a nutritional and a physiological relevance, emphasizing the necessity of a deeper investigation of the characteristics of the amino acid and peptide transport, in order to recommend the correct forms of EAA supplementation, but also the possibility of better understanding, from comparative studies, the molecular determinants involved in the main functions of the protein.

\section{Acknowledgments}

This work has been funded under the Finlombarda Project and EU seventh Framework Programme by the ARRAINA project No. 288925: Advanced Research Initiatives for Nutrition \& Aquaculture. The views expressed in this work are the sole responsibility of the authors and do not necessary reflect the views of the European Commission.

\section{References}

Binda, F., Bossi, E., Giovannardi, S., Forlani, G., Peres, A., 2002. Temperature effects on the presteady-state and transport-associated currents of GABA cotransporter rGAT1. FEBS Lett. 512, 303-307.

Bossi, E., Fabbrini, M.S., Ceriotti, A., 2007a. Exogenous protein expression in Xenopus laevis oocytes: basic procedures. In: Grandi, G. (Ed.), In Vitro Transcription and Translation Protocols. Humana Press, Totowa NJ, pp. 107-131.

Bossi, E., Soragna, A., Miszner, A., Giovannardi, S., Frangione, V., Peres, A., 2007b. Oligomeric structure of the neutral amino acid transporters KAAT1 and CAATCH1. Am. J. Physiol. Cell Physiol. 292, C1379-C1387.

Bossi, E., Renna, M.D., Sangaletti, R., D'Antoni, F., Cherubino, F., Kottra, G., Peres, A. 2011. Residues R282 and D341 act as electrostatic gates in the proton-dependent oligopeptide transporter PepT1. J. Physiol. 589, 495-510.

Bossi, E., Cherubino, F., Margheritis, E., Oyadeyi, A.S., Vollero, A., Peres, A., 2012. Temperature effects on the kinetic properties of the rabbit intestinal oligopeptide cotransporter PepT1. Pflugers Arch. 464, 183-191.

Castagna, M., Bossi, E., Sacchi, V.F., 2009. Molecular physiology of the insect K-activated amino acid transporter 1 (KAAT1) and cation-anion activated amino acid transporter/channel 1 (CAATCH1) in the light of the structure of the homologous protein LeuT. Insect Mol. Biol. 18, 265-279.

Chen, H., Pan, Y., Wong, E.A., Bloomquist, J.R., Webb Jr., K.E., 2002a. Molecular cloning and functional expression of a chicken intestinal peptide transporter (cPepT1) in Xenopus oocytes and Chinese hamster ovary cells. J. Nutr. 132, 387-393.

Chen, H., Pan, Y.X., Wong, E.A., Webb Jr., K.E., 2002b. Characterization and regulation of a cloned ovine gastrointestinal peptide transporter (oPepT1) expressed in a mammalian cell line. J. Nutr. 132, 38-42.

Daniel, H., Kottra, G., 2004. The proton oligopeptide cotransporter family SLC15 in physiology and pharmacology. Pflugers Arch. 447, 610-618.

Daniel, H., Spanier, B., Kottra, G., Weitz, D., 2006. From bacteria to man: archaic protondependent peptide transporters at work. Physiology (Bethesda) 21, 93-102.

Edelheit, O., Hanukoglu, A., Hanukoglu, I., 2009. Simple and efficient site-directed mutagenesis using two single-primer reactions in parallel to generate mutants for protein structure-function studies. BMC Biotechnol. 9, 61.

Gilbert, E.R., Wong, E.A., Webb Jr., K.E., 2008. Board-invited review: peptide absorption and utilization: implications for animal nutrition and health. J. Anim. Sci. 86, $2135-2155$.

Giovannardi, S., Soragna, A., Magagnin, S., Faravelli, L., 2007. Functional expression of type 1 rat GABA transporter in microinjected Xenopus laevis oocytes. Methods Mol. Biol. 375, 235-255.

Klang, J.E., Burnworth, L.A., Pan, Y.X., Webb Jr., K.E., Wong, E.A., 2005. Functional characterization of a cloned pig intestinal peptide transporter (pPepT1). J. Anim. Sci. 83 , $172-181$.

Kottra, G., Daniel, H., 2001. Bidirectional electrogenic transport of peptides by the proton-coupled carrier PEPT1 in Xenopus laevis oocytes: its asymmetry and symmetry. J. Physiol. 536, 495-503.

Kottra, G., Stamfort, A., Daniel, H., 2002. PEPT1 as a paradigm for membrane carriers that mediate electrogenic bidirectional transport of anionic, cationic, and neutral substrates. J. Biol. Chem. 277, 32683-32691.

Liu, H., Naismith, J.H., 2008. An efficient one-step site-directed deletion, insertion, single and multiple-site plasmid mutagenesis protocol. BMC Biotechnol. 8, 91.

Meredith, D., 2009. Review. The mammalian proton-coupled peptide cotransporter PepT1: sitting on the transporter-channel fence? Philos. Trans. R. Soc. Lond. B Biol. Sci. 364, 203-207.

Meredith, D., Price, R.A., 2006. Molecular modeling of PepT1-towards a structure. J. Membr. Biol. 213, 79-88.

Mertl, M., Daniel, H., Kottra, G., 2008. Substrate-induced changes in the density of peptide transporter PEPT1 expressed in Xenopus oocytes. Am. J. Physiol. Cell Physiol. 295, C1332-C1343.

Newstead, S., 2011. Towards a structural understanding of drug and peptide transport within the proton-dependent oligopeptide transporter (POT) family. Biochem. Soc. Trans. 39, 1353-1358.

Newstead, S., Drew, D., Cameron, A.D., Postis, V.L., Xia, X., Fowler, P.W., Ingram, J.C. Carpenter, E.P., Sansom, M.S., McPherson, M.J., Baldwin, S.A., Iwata, S., 2011. Crystal structure of a prokaryotic homologue of the mammalian oligopeptide-proton symporters, PepT1 and PepT2. EMBO J. 30, 417-426.

Pan, Y., Wong, E.A., Bloomquist, J.R., Webb Jr., K.E., 2001. Expression of a cloned ovine gastrointestinal peptide transporter (oPepT1) in Xenopus oocytes induces uptake of oligopeptides in vitro. J. Nutr. 131, 1264-1270. 
Pedretti, A., De Luca, L., Marconi, C., Negrisoli, G., Aldini, G., Vistoli, G., 2008. Modeling of the intestinal peptide transporter hPepT1 and analysis of its transport capacities by docking and pharmacophore mapping. ChemMedChem 3, 1913-1921.

Peres, A., Vollero, A., Margheritis, E., D'Antoni, F., Bossi, E., 2012. An inverse relationship links temperature and substrate apparent affinity in the ion-coupled cotransporters rGAT1 and KAAT1. Int. J. Mol. Sci. 13, 15565-15574.

Renna, M.D., Oyadeyi, A.S., Bossi, E., Kottra, G., Peres, A., 2011a. Functional and structural determinants of reverse operation in the $\mathrm{pH}$-dependent oligopeptide transporter PepT1. Cell. Mol. Life Sci. 68, 2961-2975.

Renna, M.D., Sangaletti, R., Bossi, E., Cherubino, F., Kottra, G., Peres, A., 2011b. Unified modeling of the mammalian and fish proton-dependent oligopeptide transporter PepT1. Channels (Austin) 5, 89-99.

Ronnestad, I., Gavaia, P.J., Viegas, C.S., Verri, T., Romano, A., Nilsen, T.O., Jordal, A.E. Kamisaka, Y., Cancela, M.L., 2007. Oligopeptide transporter PepT1 in Atlantic cod (Gadus morhua L.): cloning, tissue expression and comparative aspects. J. Exp. Biol. 210, 3883-3896.

Ronnestad, I., Murashita, K., Kottra, G., Jordal, A.E., Earawane, S., Jolly, C., Daniel, H., Verri, T., 2010. Molecular cloning and functional expression of Atlantic salmon peptide transporter 1 in Xenopus oocytes reveals efficient intestinal uptake of lysine-containing and other bioactive di- and tripeptides in teleost fish. J. Nutr. $140,893-900$
Sangaletti, R., Terova, G., Peres, A., Bossi, E., Cora, S., Saroglia, M., 2009. Functional expression of the oligopeptide transporter PepT1 from the sea bass (Dicentrarchus labrax). Pflugers Arch. 459, 47-54.

Solcan, N., Kwok, J., Fowler, P.W., Cameron, A.D., Drew, D., Iwata, S., Newstead, S., 2012. Alternating access mechanism in the POT family of oligopeptide transporters. EMBO J. 31, 3411-3421.

Soragna, A., Mari, S.A., Pisani, R., Peres, A., Castagna, M., Sacchi, V.F., Bossi, E., 2004 Structural domains involved in substrate selectivity in two neutral amino acid transporters. Am. J. Physiol. Cell Physiol. 287, C754-C761.

Verri, T. Kottra, G., Romano, A., Tiso, N., Peric, M., Maffia, M., Boll, M., Argenton, F. Daniel, H., Storelli, C., 2003. Molecular and functional characterisation of the zebrafish (Danio rerio) PEPT1-type peptide transporter. FEBS Lett. 549, 115-122.

Verri, T., Romano, A., Barca, A., Kottra, G., Daniel, H., Storelli, C., 2010. Transport of diand tripeptides in teleost fish intestine. Aquacult. Res. 41, 641-653.

Verri, T., Terova, G., Dabrowski, K., Saroglia, M., 2011. Peptide transport and animal growth: the fish paradigm. Biol. Lett. 7, 597-600.

Vig, B.S., Stouch, T.R., Timoszyk, J.K., Quan, Y., Wall, D.A., Smith, R.L., Faria, T.N., 2006 Human PEPT1 pharmacophore distinguishes between dipeptide transport and binding. J. Med. Chem. 49, 3636-3644.

Wang, M., Zhang, X., Zhao, H., Wang, Q., Pan, Y., 2010. Comparative analysis of vertebrate PEPT1 and PEPT2 genes. Genetica 138, 587-599. 